\title{
Las elecciones en Colombia
}

\author{
The Elections in Colombia
}

\section{Hernán Alejandro Olano García**}

\section{Sumario:}

I. El derecho al sufragio

II. La capacidad electoral

III. Pérdida del derecho a votar

IV. Atributos esenciales del sufragio en Colombia

V. Ciudadanos excluidos del cuerpo electoral

VI. Clases de elecciones

VII. Circunscripciones electorales

VIII. Sistemas para asignación de curules

IX. Causas comunes de inelegibilidad

$X$. El procedimiento electoral

XI. Bibliografía

* Abogado, con estancia Post Doctoral en Derecho Constitucional como Becario de la Fundación Carolina en la Universidad de Navarra, España; profesor de Derecho Público y director del Programa de Humanidades en la Facultad de Filosofía y Ciencias Humanas de la Universidad de La Sabana.

Resultados del autor dentro del proyecto de investigación: "Desarrollo de las Fuentes del Derecho Administrativo Colombiano", que se realiza dentro del Grupo de Investigación en Derecho, Administración Pública e Historia de las Instituciones "Diego de Torres y Moyachoque, Cacique de Turmequé", en la Universidad de La Sabana de Chía, Colombia. 


\section{Resumen:}

El presente artículo de reflexión, es uno de los resultados de investigación del proyecto titulado "Desarrollo de las fuentes del derecho administrativo en Colombia” El autor señala en diez subtítulos los aspectos más específicos del derecho electoral colombiano.

\section{Abstract:}

The present article of reflection, is one of the results of investigation of the titled project "Development of the Sources of the Administrative Right in Colombia" The author indicates in ten subtitles the most specific aspects of the Colombian Electoral Right.

Palabras clave: derecho electoral, elecciones, sufragio, clases de elecciones, derechos ciudadanos, procedimiento electoral.

Descriptors: electoral right, elections, vote, classes of elections, civil rights, electoral procedure. 


\section{El derecho al sufragio}

En Colombia, el derecho al sufragio constituye para el ciudadano un derecho público subjetivo; pero su eficacia está condicionada por el concurso de las manifestaciones de voluntad de los componentes del cuerpo electoral, que de todos modos es un agregado comunitario. Desde luego, no es necesaria la fijación de un mínimo de votantes para que se tenga como inequívoca la escogencia que haga en determinado momento dicho órgano del Estado. Quienes votan eligen, aun cuando el número de abstencionista alcance proporciones en verdad impresionantes.

El derecho del electorado activo proviene de la capacidad electoral, la cual consiste en el poder concedido por la ley a los ciudadanos y desde luego garantizado por ella, de inscribirse en un colegio electoral con el fin de participar en la función del sufragio, ya sea para elegir presidente de la República o a los integrantes de los llamados cuerpos representativos.

En Colombia, el voto es considerado como un derecho y deber ciudadano. En todas las elecciones los ciudadanos votan secretamente en cubículos individuales instalados en cada mesa de votación, con tarjetas electorales numeradas e impresas en papel que ofrece seguridad, las cuales serán distribuidas oficialmente. La organización electoral suministra igualitariamente a los votantes instrumentos en los cuales deben aparecer identificados con claridad y en iguales condiciones todos los candidatos. La ley puede implantar mecanismos de votación que otorguen más y mejores garantías para el libre ejercicio de este derecho de los ciudadanos, lo que dará plazo, a más tardar en 2014 al denominado voto electrónico.

De igual manera, el derecho al sufragio como tal, se encuentra desarrollado en el artículo 258 de la Constitución política y en la Ley 131 de $1994,{ }^{1}$ al igual que en la Ley $134^{2}$ del mismo año, estatutaria de los mecanismos de participación ciudadana.

1 Ley 131 de 1994, Congreso de la República, Colombia.

2 Idem. 
El citado artículo 258 Superior, ${ }^{3}$ luego de la Reforma Política, Acto Legislativo 01 de 2003, ${ }^{4}$ y del ajuste con el Acto Legislativo 01 de 2009, ${ }^{5}$ quedó así:

Artículo 258. Modificado por el artículo 11 del A. L. 1 de 2003. Modificado el Parágrafo 1o. por el artículo 9 del A. L. 1 de 2009. El voto es un derecho y un deber ciudadano. El Estado velará porque se ejerza sin ningún tipo de coacción y en forma secreta por los ciudadanos en cubículos individuales instalados en cada mesa de votación sin perjuicio del uso de medios electrónicos o informáticos. En las elecciones de candidatos podrán emplearse tarjetas electorales numeradas e impresas en papel que ofrezca seguridad, las cuales serán distribuidas oficialmente. La Organización Electoral suministrará igualitariamente a los votantes instrumentos en los cuales deben aparecer identificados con claridad y en iguales condiciones los movimientos y partidos políticos con personería jurídica y los candidatos. La ley podrá implantar mecanismos de votación que otorguen más y mejores garantías para el libre ejercicio de este derecho de los ciudadanos.

Parágrafo 1o. Deberá repetirse por una sola vez la votación para elegir miembros de una Corporación Pública, Gobernador, Alcalde o la primera vuelta en las elecciones presidenciales, cuando del total de votos válidos, los votos en blanco constituyan la mayoría. Tratándose de elecciones unipersonales no podrán presentarse los mismos candidatos, mientras en las de Corporaciones Públicas no se podrán presentar a las nuevas elecciones las listas que no hayan alcanzado el umbral.

Parágrafo 2o. Se podrá implementar el voto electrónico para lograr agilidad y transparencia en todas las votaciones.

\section{La capacidad electoral}

Depende de los requisitos que para tal efecto señale la ley, siendo criterios principales para su determinación, la nacionalidad y la edad.

3 Olano García, Hernán Alejandro, Constitución Política de Colombia-concordada, 2a. ed., Bogotá, Ediciones Doctrina y Ley, 2011.

4 Acto Legislativo 01 de 2003, Congreso de la República, Colombia.

5 Acto Legislativo 01 de 2009, Congreso de la República, Colombia. 
El artículo 99 de la Constitución ${ }^{6}$ - por ejemplo- dispone que la "calidad de ciudadano en ejercicio es condición previa, indispensable para elegir y ser elegido y para desempeñar empleos públicos que lleven anexa autoridad o jurisdicción", luego de preceptuar en el artículo 98 de la misma obra ${ }^{7}$ que "son ciudadanos los colombianos mayores de 18 años", con la aclaración precisada en la misma norma de que "la ciudadanía se pierde de hecho cuando se ha perdido la nacionalidad o en virtud de decisión judicial en los casos que determinen las leyes".

Siguiendo con el caso colombiano, que es el que nos ocupa, los ciudadanos eligen en forma directa presidente y vicepresidente de la República, senadores, representantes, gobernadores, diputados, alcaldes, concejales municipales y distritales, miembros de las juntas administradoras locales, jueces de paz y en su oportunidad, a los miembros de la Asamblea Constituyente y las demás autoridades o funcionarios que la Constitución señale.

Quienes elijan gobernadores y alcaldes, imponen por mandato al elegido el programa que presentó al inscribirse como candidato; es lo que se conoce como el voto programático, que puede dar lugar a la revocatoria del mandato, reconocido también por la propia Constitución como un mecanismo de participación popular.

La Ley 131 de $1994,{ }^{8}$ sobre este particular dice:

Artículo 3o. Los candidatos a ser elegidos como gobernadores y alcaldes deberán someter a consideración ciudadana un programa de gobierno, que hará parte integral de la inscripción ante las autoridades electorales respectivas, debiéndose surtir posteriormente su publicación en el órgano oficial de la entidad territorial respectiva o, en su defecto, las administraciones departamentales o municipales ordenarán editar una publicación donde se den a conocer los programas de todos los aspirantes, sin prejuicio de su divulgación pública de acuerdo con la reglamentación en materia de uso de medios de comunicación.

En desarrollo del artículo 259 de la Constitución Política de Colombia, ${ }^{9}$ se entiende por voto programático el mecanismo de participación mediante el cual los ciudadanos que votan para elegir alcaldes y gobernadores, imponen como mandato al elegido el cumplimiento del

6 Olano García, Hernán Alejandro, op. cit.

7 Idem.

${ }^{8}$ Ley 131 de 1994, Congreso de la República, Colombia, en: www.noti.net.

9 Olano García, Hernán Alejandro, op. cit. 
programa de gobierno que haya presentado como parte integral en la inscripción de su candidatura.

Por su parte, las faltas absolutas o temporales de los elegidos, serán suplidas por los candidatos que según el orden de inscripción en forma sucesiva y descendente, correspondan a la misma lista electoral.

Son faltas absolutas: además de las establecidas por la ley, las que se causan por: muerte; la renuncia motivada y aceptada por la plenaria de la respectiva Corporación; la pérdida de la investidura; la incapacidad física permanente, y la sentencia condenatoria en firme dictada por autoridad judicial competente.

Son faltas temporales las causadas por: la suspensión del ejercicio de la investidura popular, en virtud de decisión judicial en firme; la licencia sin remuneración (que no podrá ser inferior a tres meses); la licencia por incapacidad certificada por médico oficial; la calamidad doméstica debidamente probada y la fuerza mayor.

Los casos de incapacidad, calamidad doméstica y licencias no remuneradas, deberán ser aprobadas por la Mesa Directiva de la respectiva Corporación, Senado o Cámara de Representantes, Asamblea Departamental, Concejo Municipal y Junta Administradora Local.

\section{Pérdida del derecho a votar}

Todos los ciudadanos que llenen los dos requisitos aludidos anteriormente (que tengan mayoría de edad para efectos del sufragio) son electores, a menos que se hallen colocados en ciertas situaciones que conllevan la pérdida de ese derecho, destacándose en todo caso las siguientes: los interdictos por enfermedad mental, es decir, los individuos que han sido declarados como tales por la autoridad competente en razón de alteraciones sufridas en su capacidad de entender o de querer; los condenados a la pérdida de los derechos políticos como pena accesoria de una sanción más grave como la de presidio o prisión, caso en el cual la interdicción de derechos y funciones públicas se impone por el tiempo igual al de la pena principal, como ocurre en Colombia, y los sujetos que adquieran carta de naturaleza en otra nación, que renuncien a la nacionalidad colombiana, según lo dispone la Ley 43 de 1993, ${ }^{10}$ donde se establece que el desempeño de funciones y cargos públicos de los nacionales por adopción que tengan otra na-

${ }_{10}$ Ley 43 de 1993, Congreso de la República, Colombia. 
cionalidad vigente, podrán ser limitados en los términos previstos en la Constitución y en la ley. Esos cargos son:

a) Presidente o vicepresidente de la República.

b) Senadores de la República.

c) Magistrados de la Corte Constitucional, Corte Suprema de Justicia y Consejo Superior de la Judicatura.

d) Fiscal general de la nación.

e) Miembros del Consejo Nacional Electoral y Registrador Nacional del Estado Civil.

f) Contralor general de la República.

g) Procurador general de la nación.

h) Ministros de relaciones exteriores y de defensa nacional.

i) Directores de organismos de inteligencia y seguridad.

Para el caso de los extranjeros residentes en Colombia, el segundo inciso del artículo 100 Superior, consagra: "Los derechos políticos se reservan a los nacionales, pero la ley podrá conceder a los extranjeros residentes en Colombia el derecho al voto en las elecciones y consultas populares de carácter municipal o distrital"; ${ }^{11}$ ese es el gran compromiso de permitir un espacio participativo y de construcción de un alto nivel de interrelación de los diferentes actores sociales, responsables y activos en el proceso de edificación de la democracia en todos los escalones de la sociedad civil.

\section{Atributos esenciales del sufragio en Colombia}

Para que el sufragio se pueda considerar como la expresión auténtica de la voluntad popular debe ser:

\section{Universal (de todos los ciudadanos)}

Esto no quiere decir que la universalidad del sufragio sea absoluta. En todos los países tanto la Constitución como las leyes respectivas exi-

${ }^{11}$ Olano García, Hernán Alejandro, op. cit. 
gen un mínimo de condiciones necesarias para que los miembros del cuerpo electoral puedan votar, como las referentes a la nacionalidad y a la edad ya mencionadas, lo mismo que a ciertos requisitos morales de los electores.

Lo no aceptado ni aceptable, en manera alguna, es que el ejercicio del voto pueda estar subordinado a factores raciales, culturales, religiosos, económicos o sociales, ni mucho menos la diferencia de sexo. El estar exento de tales condicionamientos es lo que permite hablar de la universalidad del sufragio.

En Colombia, lo mismo que en la mayoría de los países, la edad requerida para el ejercicio del sufragio se bajó de 21 a 18 años desde 1977. ${ }^{12}$

Referente al voto de los militares, las opiniones son contrapuestas. Diversos tratadistas conceptúan que si se les concede el derecho del voto a los militares se corre el riesgo de que intenten jugar un rol intenso en la actividad política hasta el punto de poner en peligro al gobierno civil, o por lo menos de afectar la indispensable disciplina castrense.

Para otros autores ese derecho es imperativo y al serle negado a los miembros de las fuerzas armadas prácticamente se les está desconociendo su calidad de ciudadanos, tesis que se aceptó en la República Bolivariana de Venezuela por parte de su presidente, el coronel Hugo Chávez.

En realidad una u otra posición depende del concepto existente en torno a los tipos de Estado. En las democracias clásicas predomina la tendencia a sustraer a los militares del ejercicio del sufragio, en tanto que les es concedido, sin restricción específica alguna, en las llamadas democracias populares.

\section{Igual}

Esta condición se refiere no sólo a que todos los ciudadanos deben votar, sino a que el sufragio de cada uno de ellos tiene el mismo valor. De ahí el apotegma de que los votos se cuentan, no se pesan. La igualdad del voto excluye por lo alto las figuras del voto plúrimo (atribuciones para que un sujeto pueda depositar varios votos en una sola urna) lo

12 Acto Legislativo 01 de 1977, Congreso de la República, Colombia. 
mismo que del voto múltiple (posibilidad de que el elector pueda votar en más de una circunscripción electoral).

\section{Secreto}

Este requisito tiene como finalidad sustraer al elector de las coacciones, los temores reverenciales y las represalias.

Autores tan insignes como Stuart Mill y Montesquieu se pronunciaron en su tiempo a favor del voto público, no secreto, aduciendo como razón que permitiría a las personas cultas y autorizadas dar ejemplo valiosísimo a los vacilantes en torno a la responsabilidad que implica el acto de poder votar. Sin embargo esta tendencia fue superada en tal forma que hoy todos los Estados han acogido la tesis del voto secreto para preservar la libertad de los electores, sobre todo de quienes se encuentren en condiciones de dependencia jerárquica, económica o social con relación a otros sujetos.

El frustrado referendo de 2003, previó el voto nominal y público, salvo para asuntos de mero trámite, impuesto a los elegidos en cualquiera de las corporaciones públicas, modificando el artículo 133 Superior; ${ }^{13}$ sin embargo, en 2009 se daría otro ajuste constitucional, que dejó el texto al siguiente tenor:

Artículo 133. Modificado por el artículo 5 del A.L. 1 de 2009.

Los miembros de cuerpos colegiados de elección directa representan al pueblo, y deberán actuar consultando la justicia y el bien común. El voto de sus miembros será nominal y público, excepto en los casos que determine la Ley.

El elegido es responsable políticamente ante la sociedad y frente a sus electores del cumplimiento de las obligaciones propias de su investidura.

\section{Personal}

Se dice que el voto es personal cuando el elector ejerce el derecho del sufragio por sí mismo, excluyendo el voto por correspondencia o por otro medio que implique la figura del mandato.

${ }^{13}$ Olano García, Hernán Alejandro, op. cit. 
El carácter personal del voto también es incompatible con el llamado voto familiar, cuya esencia era la de que el jefe del hogar podía sufragar en cada elección tantas veces cuantos descendientes estuvieran a su cargo, conforme a la fórmula "una vida, un voto".

\section{Facultativo}

El voto facultativo corresponde a un sistema que deja libre a cada elector para sufragar por el candidato o candidatos de su preferencia o para abstenerse de ejercer ese derecho.

La libertad del voto consiste, pues, en que no haya presión de ninguna naturaleza sobre el elector, ya sea física, económica o moral, y también en que la decisión de sufragar se deje a la conciencia y responsabilidad de cada cual. Sobre todo en cuadros de obreros no sindicalizados se les oye decir a muchos con pesadumbre no exenta de actitud: "nosotros votamos por el pan", dejando entrever la existencia oculta de presiones de carácter económico. Sin embargo, es preciso distinguir las presiones propiamente dichas de la simple propaganda política, cuya esencia está conformada por las técnicas cada día más sofisticadas y costosas de la publicidad hablada y escrita.

En numerosos países como Colombia, la abstención electoral ha alcanzado cifras alarmantes, dejando entrever un crudo escepticismo político o una desdeñosa indiferencia cuya causa más profunda es la falta de integración real de los ciudadanos dentro del marco institucional del Estado, esto es, la ausencia prohijada de la democracia gobernante.

Para combatir la abstención, el Congreso de Colombia expidió las leyes 403 de 1997,,${ }^{14}$ y 815 de 2003,,${ }^{15}$ las cuales establecen que la participación mediante el voto en la vida política, cívica y comunitaria se considera una actitud positiva de apoyo a las instituciones democráticas, y como tal será reconocida, facilitada y estimulada por las autoridades.

Así es como todo ciudadano que ejerza el derecho al voto en forma legítima en las elecciones y en los eventos relacionados con los demás mecanismos de participación constitucionalmente autorizados, gozará de una serie de beneficios que las citadas leyes consagran, entre los cuales están:

14 Ley 403 de 1997, Congreso de la República, Colombia.

15 Ley 815 de 2003, Congreso de la República, Colombia. 
- El estudiante de institución oficial de educación superior tendrá derecho a un descuento del $10 \%$ del costo de la matrícula, si acredita haber sufragado en la última votación realizada con anterioridad al inicio de los respectivos periodos académicos. La Ley 815 aclaró el alcance del numeral 5 del artículo 2o. de la Ley 403 de 1997 en el siguiente entendido: el descuento del 10\% en el valor de la matrícula a que tiene derecho el estudiante de institución oficial de educación superior, como beneficio por el ejercicio del sufragio, se hará efectivo no sólo en el periodo académico inmediatamente siguiente al ejercicio del sufragio sino en todos los periodos académicos que tengan lugar hasta las votaciones siguientes en que pueda participar. Como una contribución a la formación de buenos ciudadanos, las universidades no oficiales podrán establecer, dentro de sus estrategias de mercadeo, un descuento en el valor de la matrícula a los estudiantes de pregrado y posgrado que acrediten haber sufragado en las últimas elecciones o eventos de participación ciudadana directa. Las universidades que voluntariamente establezcan el descuento en la matrícula no podrán trasladar a los estudiantes el valor descontado ni imputarlo como costo adicional en los reajustes periódicos legalmente autorizados. El gobierno otorgará reconocimientos especiales e incentivos a las universidades que den aplicación al estímulo electoral previsto en este numeral.

- Quien haya ejercido el derecho al sufragio se beneficiará, por una sola vez, de una rebaja del $10 \%$ en el valor de expedición del pasaporte que solicite durante los cuatro años siguientes a la votación. Este porcentaje se descontará del valor del pasaporte que se destina a la nación.

- Quien hubiera ejercido el derecho al voto en la elección inmediatamente anterior tendrá derecho a ser preferido, frente a quienes injustificadamente no lo hicieron, en la adjudicación de becas educativas, de predios rurales y de subsidios de vivienda que ofrezca el Estado, en caso de igualdad de condiciones estrictamente establecidas en concurso abierto.

- Quien hubiere participado en la votación inmediatamente anterior tendrá derecho a ser preferido, frente a quienes injustificadamente no lo hubieren hecho, en caso de igualdad de puntaje en la lista de elegibles para un empleo de carrera del Estado. 
- Quien hubiere participado en las votaciones inmediatamente anteriores tendrá derecho a ser preferido, frente a quienes injustificadamente no lo hayan hecho, en caso de igualdad de puntaje en los exámenes de ingreso a las instituciones públicas o privadas de educación superior.

- Quien hubiere participado en las votaciones inmediatamente anteriores al reclutamiento en el servicio militar tendrá derecho a una rebaja de un mes en el tiempo de prestación de este servicio, cuando se trate de soldados bachilleres o auxiliares de policía bachiller, y de dos meses, cuando se trate de soldados campesinos o soldados regulares.

- Quien acredite haber sufragado tendrá derecho a los siguientes descuentos durante el tiempo que transcurra hasta las siguientes votaciones:

a) $10 \%$ del valor a cancelar por concepto de trámite de expedición inicial y renovación del pasado judicial.

b) $10 \%$ del valor a cancelar por concepto de trámite inicial y expedición de duplicados de la libreta militar.

c) $10 \%$ del valor a cancelar por duplicados de la cédula de ciudadanía del segundo duplicado en adelante.

- Los colombianos que ejerzan el derecho al sufragio en el exterior tendrán los siguientes incentivos especiales:

a) Descuento del $10 \%$ en el valor de cualquier servicio consular, incluida la expedición del pasaporte.

b) Descuento del 30\% en el impuesto de salida del país cuando el ciudadano lo visite por un término máximo de 45 días.

- El ciudadano tendrá derecho a media jornada de descanso compensatorio remunerado por el tiempo que utilice para cumplir su función como elector. Tal descanso compensatorio se disfrutará en el mes siguiente al día de la votación, de común acuerdo con el empleador.

De igual manera, el Decreto 2559 del 17 de octubre de 1997, ${ }^{16}$ redactado por el suscrito, reglamenta la Ley 403 y define y hace operativos los beneficios al elector, así como establece lo que es el certificado

16 Decreto 2559 de 1997, Congreso de la República, Colombia. 
electoral, que se entrega al votante para dar fe que su titular cumplió con el deber de votar en las correspondientes elecciones.

\section{Ciudadanos excluidos del cuerpo electoral}

En particular pueden ser excluidos del registro electoral, conforme a la legislación de diferentes países, quienes se encuentren en cualquiera de las situaciones siguientes:

- Los civilmente incapaces, es decir los interdictos e inhabilitados por enfermedad de la mente.

- Los militares.

- Los condenados a penas aflictivas de presidio o prisión hasta el día de su rehabilitación en el ejercicio de los derechos políticos.

- Los que hayan adquirido carta de naturaleza en otro país y no hayan realizado rehabilitación de la ciudadanía y de la nacionalidad.

\section{Clases de elecciones}

La Constitución determina tres clases de elecciones, cuya fecha separada de realización corresponde fijar a la ley para el uso colombiano:

a) Para presidente y vicepresidente de la República.

b) Para miembros del Congreso (senadores y representantes).

c) Para autoridades departamentales y municipales (gobernadores, diputados, alcaldes y concejales).

Este marco obedece a propósitos democráticos, aunque ha sido criticada la gran frecuencia de elecciones por los costos que estas implican para el país debido a su frecuencia.

Es así como según el artículo 262 Superior, ${ }^{17}$ la elección del presidente y vicepresidente no podrá coincidir con otra elección. La de Congreso se hará en fecha separada de la elección de autoridades departamentales y municipales.

17 Olano García, Hernán Alejandro, op. cit. 
La disposición del artículo 263 Superior, ${ }^{18}$ indica que para las elecciones, debe aplicarse un sistema de Lista Única, de acuerdo con el número de partidos y movimientos políticos existentes y de cargos a proveer, y ciertos porcentajes que modificarán la asignación por requerirse del umbral y la cifra repartidora mínimas:

Artículo 263. Modificado por el artículo 11 del A.L. 1 de 2009.

Para todos los procesos de elección popular, los partidos y movimientos políticos presentarán listas y candidatos únicos, cuyo número de integrantes no podrá exceder el de curules o cargos a proveer en la respectiva elección. Para garantizar la equitativa representación de los partidos y movimientos políticos y grupos significativos de ciudadanos, las curules de las Corporaciones Públicas se distribuirán mediante el sistema de cifra repartidora entre las listas de candidatos que superen un mínimo de votos que no podrá ser inferior al tres por ciento (3\%) de los sufragados para Senado de la República o al cincuenta por ciento (50\%) del cuociente electoral en el caso de las demás Corporaciones, conforme lo establezcan la Constitución y la Ley.

Cuando ninguna de las listas de aspirantes supere el umbral, las curules se distribuirán de acuerdo con el sistema de cifra repartidora.

La Ley reglamentará los demás efectos de esta materia.

Las listas para Corporaciones en las circunscripciones en la que se eligen hasta dos (2) miembros para la correspondiente Corporación, podrán estar integradas hasta por tres (3) candidatos. En las circunscripciones en las que se elige un miembro, la curul se adjudicará a la lista mayoritaria. En las circunscripciones en las que se eligen dos miembros se aplicará el sistema de cuociente electoral entre las listas que superen en votos el 30\% de dicho cuociente.

Parágrafo Transitorio: Para las elecciones al Congreso de la República a celebrarse en 2010, el porcentaje a que se refiere el inciso segundo del presente artículo será del dos por ciento (2\%).

\section{Circunscripciones electorales}

En los grandes Estados modernos, sobre todo para la elección de los miembros de cuerpos colegiados, es muy cercano a lo imposible lo-

18 Idem. 
grar que voten todos los ciudadanos en una sola circunscripción electoral que vendría a confundirse con el territorio nacional.

Al contrario, el territorio de cada país, para asuntos electorales, se divide en varias circunscripciones de este carácter con el fin de facilitar, ordenar y controlar la función del sufragio y, también, para que todas las regiones obtengan la debida representación en los diversos cuerpos colegiados estatuidos por la ley superior correspondiente.

Los diferentes ordenamientos jurídicos de los Estados tienden a buscar el sistema que garantice, en cada circunscripción, la proporcionalidad más rigurosa entre el número de curules por proveer y el número de electores inscritos.

Para obtener la debida proporcionalidad entre el número de curules por proveer y la población de las circunscripciones, existen dos métodos principales:

1) El primer método consiste en dividir artificialmente el territorio del país para efectos de la función electoral. La operación es muy sencilla: se estructura cierto número de circunscripciones aproximadamente con el mismo número de electores para que puedan elegir (cada una) el mismo número de representantes o diputados. A primera vista este método tiene la ventaja de su sencillez, pero tiene serios inconvenientes. El partido que la lleva a cabo por regla general es el que está en el poder, y, en tales circunstancias, su interés de aliento más vivo es mantener y consolidar la posición mayoritaria que ha conquistado a costa de duras batallas. Por lo demás, el funcionamiento concreto de estas circunscripciones ficticias y pasajeras, en la mayoría de los casos, está colmado de dificultades de distinto género, no siendo de menor importancia la referente al aumento o disminución impredecibles del volumen de sus habitantes, partiendo de una determinada fecha comicial a otra.

2) Un método distinto consiste en hacer coincidir las circunscripciones electorales con las divisiones de carácter administrativo, en torno a distritos y departamentos, como ocurre - verbigracia- en las repúblicas francesa, colombiana y española. Este método tiende a eliminar los riesgos de divisiones arbitrales, así como las dificultades que se advierten en su funcionamiento, aunque no siempre coinciden la población real y el número de representantes o diputados de cada una de las circunscripciones.

De todos modos la respuesta a los problemas que se dejan reseñados adquiere particular importancia según el tipo de escrutinio que se adopte, ya sea el uninominal o el escrutinio de lista. 
1) El escrutinio uninominal. Se basa en que el elector no vota sino por un solo nombre, en razón a que la circunscripción electoral en la cual está inscrito elige únicamente un representante o diputado. En Francia, por ejemplo, hay circunscripciones de distrito, de modo que el escrutinio uninominal también puede ser de distrito.

Los defensores del escrutinio uninominal presentan estos argumentos:

Permite que los electores participen más directamente en la escogencia de sus representantes, lo que entraña una elección más consciente y diáfana. Por cuanto el distrito corresponde a una circunscripción reducida, el elector tiene oportunidad de conocer personalmente a cada candidato, lo cual no ocurre en el marco de un departamento en donde es casi imposible que cada elector se forme una idea clara de los candidatos de todas y cada una de las listas.

El torneo comicial es menos costoso en una decisión de distrito que en la de un departamento. El escrutinio uninominal por distritos protege la soberanía individual del elector contra la absorción de las asociaciones políticas, con el escrutinio por departamentos solo tienen posibilidad de ser elegidos quienes figuran en la lista de un gran partido político, lo cual determina el completo predominio del partido sobre el representante o diputado hasta el punto que éste se considera más del partido que del elector.

2) El escrutinio de lista. Tiene éste la característica esencial de que el elector vota por varios nombres en razón a que en su circunscripción electoral se eligen varios representantes o diputados. En Colombia el escrutinio de lista para elegir representantes y diputados se hace por departamentos. En Francia bajo la IV República se optó por el escrutinio de lista, en tanto que en la V se prefirió el sistema del escrutinio uninominal.

Los partidarios del escrutinio de lista defienden tal procedimiento aduciendo las siguientes razones:

El escrutinio uninominal lo es de personas y no de ideas. El elector vota por un candidato no propiamente en razón de su programa sino por algunos atributos personales que lo distinguen.

Se vota por " $\mathrm{X}$ " teniendo en cuenta sus apellidos, porque lo distinguen algunos títulos profesionales; porque tiene alguna notoriedad local; porque es dueño de considerables bienes de fortuna; porque se ha convertido o está próximo a convertirse en cacique regional. Si el 
escrutinio uninominal impide la dictadura del partido político, es impotente contra la dictadura personal del representante o diputado.

Por otra parte, el distrito - en razón de tener un marco estrechofacilita las presiones de la administración sobre los electores. Además el escrutinio uninominal restringe el horizonte político del elector a los límites del distrito. De ahí que el insigne orador galo - Gambetta- dijera en su tiempo al enjuiciar tal sistema, que no era otra cosa que "un espejo roto en el que Francia no podría reconocer su verdadera imagen". ${ }^{19}$

Se arguye también que el escrutinio uninominal quebranta la proporcionalidad de la representación entre las diferentes circunscripciones electorales, puesto que en cada una de ellas - cualesquiera que sea su población- no se puede elegir sino un solo representante o diputado.

En cambio, el escrutinio de lista permite variar, al menos dentro de ciertos límites, el número de representantes o diputados en consonancia con el volumen de la población correspondiente.

Otro argumento de peso contra el escrutinio uninominal es que las fuerzas políticas minoritarias en cada distrito quedan sin representación parlamentaria, pese a que la igualdad democrática exige que todos los grupos de alguna significación estén representados en los cuerpos colegiados, no sólo el que tiene la mayoría sino también las agrupaciones políticas minoritarias. Esta exigencia democrática se puede atender con éxito a través del escrutinio de listas por departamentos.

\section{Sistemas para asignación de curules}

De acuerdo con el artículo 13 del Acto Legislativo 01 de $2003,{ }^{20}$ la Constitución Política de Colombia tiene ahora un artículo nuevo, el 263-A, ${ }^{21}$ del siguiente tenor:

19 Olano Valderrama, Carlos Alberto y Olano García, Hernán Alejandro, Derecho constitucional general e instituciones políticas. Estado social de derecho, 3a. ed., Bogotá, Ediciones Librería del Profesional, 2000, p. 315.

20 Acto Legislativo 01 de 2003, Congreso de la República, Colombia.

${ }_{21}$ Olano García, Hernán Alejandro, op. cit. 
Artículo 263-A. Adicionado por el artículo 13 del A.L. 1 de 2003. La adjudicación de curules entre los miembros de la respectiva corporación se hará por el sistema de cifra repartidora. Esta resulta de dividir sucesivamente por uno, dos, tres o más el número de votos obtenidos por cada lista, ordenando los resultados en forma decreciente hasta que se obtenga un número total de resultados igual al número de curules a proveer.

El resultado menor se llamará cifra repartidora. Cada lista obtendrá tantas curules como veces esté contenida la cifra repartidora en el total de sus votos.

Cada partido o movimiento político podrá optar por el mecanismo de voto preferente. En tal caso, el elector podrá señalar el candidato de su preferencia entre los nombres de la lista que aparezcan en la tarjeta electoral. La lista se reordenará de acuerdo con la cantidad de votos obtenidos por cada uno de los candidatos. La asignación de curules entre los miembros de la respectiva lista se hará en orden descendente empezando por el candidato que haya obtenido el mayor número de votos preferentes.

En el caso de los partidos y movimientos políticos que hayan optado por el mecanismo del voto preferente, los votos por el partido o movimiento que no hayan sido atribuidos por el elector a ningún candidato en particular, se contabilizarán a favor de la respectiva lista para efectos de la aplicación de las normas sobre el umbral y la cifra repartidora, pero no se computarán para la reordenación de la lista. Cuando el elector vote simultáneamente por el partido o movimiento político y por el candidato de su preferencia dentro de la respectiva lista, el voto será válido y se computará a favor del candidato.

Para la adjudicación de listas, encontramos varios sistemas, que aquí se explican:

\section{A. Sistema mayoritario}

Ese sistema funciona mediante dos métodos principales:

\section{a. Mayoritario puro}

Se aplica cuidadosamente en Gran Bretaña. Este método consiste sencillamente en que triunfa el candidato que en la respectiva circunscripción uninominal alcance la mayoría relativa. 
b. Mayoritario con nuevo escrutinio en la segunda votación

Este método es el escogido por la V República francesa y consiste en lo siguiente: para ser elegido un candidato que aspira a la representación popular es necesario que en la primera votación alcance la mayoría absoluta (mitad más uno) de los electores inscritos en los registros de la respectiva circunscripción electoral. Si este requisito no se alcanza en la primera votación, a los quince días se procede a una segunda vuelta comicial, pero en torno únicamente a los dos candidatos que en la justa electoral precedente hayan alcanzado el mayor número de sufragios. En el segundo escrutinio obtendrá la victoria el candidato que obtenga la simple mayoría relativa.

\section{B. Sistema de la representación proporcional}

Este sistema se propone asegurar a las diversas corrientes políticas un número de curules que correspondan con la mayor exactitud a su fuerza numérica.

El sistema consiste en la votación por listas concurrentes que presentan los diversos grupos de electores (ordinariamente los partidos públicos) con el fin de que en cada circunscripción, los candidatos sean elegidos en proporción a los votos que obtenga cada lista. Entre los países que han adoptado el criterio de la representación proporcional, se cuentan Colombia y España.

La asignación proporcional de las curules para cada lista se puede llevar a cabo mediante dos métodos principales:

\section{a. Método D'Hondt o del divisor común}

Su mecanismo es el siguiente: el total de los votos obtenidos por cada lista se divide sucesivamente entre uno, dos, tres, cuatro, cinco, etcétera, hasta la concurrencia del número de curules que se deban proveer, y luego se escogen dentro de los cocientes así obtenidos, los que representen cifras más altas y en igual número al de los representantes o diputados por elegir, colocándolos en gradación descendente, es decir, que a cada lista se le asignarán tantas curules cuantos sean los cocientes que a aquellas correspondan en dicha operación gradual.

El último cociente será el divisor común, con base en el cual es fácil efectuar la prueba. 
Veamos un ejemplo:

En el municipio de Panqueva, Boyacá, se elegirán ocho concejales y hay inscritas seis listas con voto preferente. El día de elecciones, cada una de las listas obtuvo la siguiente votación:

$\begin{array}{ll}\text { Partido Tigre: } & 491 \text { votos } \\ \text { Partido Marrano } & 317 \text { votos } \\ \text { Partido Chulo } & 808 \text { votos } \\ \text { Partido Burro } & 312 \text { votos } \\ \text { Partido Zorro } & 1800 \text { votos } \\ \text { Partido Víbora } & 1688 \text { votos } \\ \text { = Votos por listas } & 5416\end{array}$

Votos en Blanco 286

Votos nulos $\quad 69$

Total votos 5771

Tarjetas no marcadas $\quad 46$

En primer lugar se calculan los votos válidos = votos por listas + votos en blanco.

Ejemplo: $5416+286=5702$ votos válidos.

Después se calcula el cociente y con base en éste se calcula el umbral, así: votos válidos dividido por puestos a proveer y luego todo dividido en dos.

Ejemplo: $5702 / 8$ curules $=713$ votos es el cociente, y $713 / 2=357$ votos es el umbral.

En tercer lugar se ordena la votación de cada partido en orden descendente con base en la siguiente matriz:

\begin{tabular}{|c|c|c|c|c|c|c|c|c|}
\hline $\begin{array}{c}\text { Nombre } \\
\text { del partido }\end{array}$ & 1 & 2 & 3 & 4 & 5 & 6 & 7 & 8 \\
\hline Zorro & 1800 & 900 & 600 & 450 & 360 & 300 & 257,1 & 225 \\
\hline Víbora & 1688 & 844 & 562,6 & 422 & 337,6 & 281,3 & 241,1 & 211 \\
\hline Chulo & 808 & 404 & 269,3 & 202 & 161,6 & 134,6 & 115,4 & 101 \\
\hline Tigre & 491 & 245,5 & 163,6 & 122,8 & 98,2 & 81,8 & 70,1 & 61,4 \\
\hline Marrano & 317 & 158,5 & 105,7 & 79,3 & 63,4 & 52,8 & 45,3 & 39,6 \\
\hline Burro & 312 & 156 & 104 & 78 & 62,4 & 52 & 44,6 & 39 \\
\hline
\end{tabular}


En cuarto lugar se encuentra cuál es la cifra repartidora, teniendo en cuenta que son ocho las curules a proveer. Esto se obtiene dividiendo el número de votos de cada lista entre uno, dos, etcétera, hasta ocho, que es el número de curules a proveer. La octava cifra más alta hallada en la división, será la cifra repartidora, que para nuestro ejemplo es 450 .

Finalmente, de acuerdo con la cifra repartidora obtenida, se sabrá cuántas curules le corresponde a cada partido dividiendo el número de sus votos por la cifra repartidora:

$\begin{array}{ll}\text { Partido Zorro } 1800 / 450= & 4 \text { curules } \\ \text { Partido Víbora } 1688 / 450= & 3.75 \text { curules } \\ \text { Partido Chulo } 808 / 450= & 1.79 \text { curules }\end{array}$

Entonces, las curules se asignarán así: Partido Zorro, 4; Partido Víbora, 3, y Partido Chulo, 1.

\section{b. Método del cociente electoral}

Al emplearse este método, la operación consiste en lo siguiente: el total de los votos válidos obtenidos por todas las listas (cifra global de sufragios en cada circunscripción) se divide por el número de curules que se van a proveer, obteniéndose así el cociente electoral. Conocido este, se elegirán tantos senadores, representantes, diputados o concejales por cada lista según las veces que el cociente electoral entre en la cifra de votos obtenida por cada una de ellas.

Si el juego del cociente electoral no alcanza a cubrir el número de curules que es necesario proveer por cada circunscripción, se tendrán en cuenta los residuos mayores hasta cubrir la totalidad de aquellas.

Ejemplo: se trata de adjudicar 2 curules de senadores entre las listas A, B y C, por la circunscripción electoral especial indígena. La lista A obtuvo 150000 votos; la lista B 90000 votos, y la lista C 70000 votos. De acuerdo con el método del cociente electoral ¿cuántos representantes sacó cada una de las listas? Sumando la totalidad de los sufragios emitidos, estos alcanzarían a 310000 votos. Dividiendo esta cifra por 2 que en el ejemplo indicado es el número de curules por proveer, se tendría el cociente electoral, o sea 155000 . Luego se divide el número de votos que obtuvo cada lista por el cociente mencionado 
y así se sabrá el número de representantes que le corresponde a cada una de las listas.

El cociente será el número que resulte de dividir el total de votos válidos por el de puestos por proveer, es como se le ha definido en Colombia y, además, si se tratare de la elección de sólo dos individuos, el cociente será la cifra que resulte de dividir el total de votos válidos por el de puestos por proveer, más uno.

La adjudicación de puestos a cada lista se hará en proporción a las veces que el cociente quepa en el respectivo número de votos válidos. Si quedaren puestos por proveer se adjudicarán a los residuos, en orden descendente.

Por su parte, el doctor Álvaro Enrique Figueroa Jiménez en su obra Derecho, elecciones y democracia en Colombia, ${ }^{22}$ distingue en las distintas legislaciones electorales tres tipos de cocientes, a saber:

- El cociente por circunscripción, o cociente propiamente dicho, que es el resultado de dividir el número de votos emitidos por el número de escaños por llenar. En él, cada lista obtiene tantos escaños como veces contiene el número de sufragios que ha recibido el cociente.

- El cociente fijo: o número uniforme que es el número de votos, fijado de antemano para el conjunto del territorio, y que cada lista debe reunir para tener derecho a una curul en la circunscripción que se presenta. Le serán atribuidos tantos escaños como veces contenga este número la suma de sufragios de la lista.

- El cociente nacional: que es el resultado de la división del conjunto de los votos emitidos en todas las circunscripciones, por el conjunto de curules que hay que elegir. El cociente así obtenido se utiliza como número uniforme. Este sistema permite que el número de curules o mandatos obtenidos por cada partido, sea proporcional al favor que ha encontrado en los electores del país entero.

\section{El sistema mixto}

El sistema mixto intenta conciliar los dos que fueron enunciados anteriormente, tratando de armonizar, por un lado, la representación de las grandes corrientes políticas que agitan en un momento dado la

22 Bogotá, D.C., Editorial Tribuna-Textos Jurídicos, 1997. 
vida del país; por otro, un mayor acercamiento de los electores en relación con los elegidos, y, por último, una independencia más real de estos frente al partido con el cual están comprometidos.

Dos son los métodos principales ideados para tal fin.

- El método Hare, o del voto transferible (adoptado en Irlanda y en algunos estados de Norteamérica) cuyo mecanismo es el siguiente: el elector sufraga a favor de determinado candidato (voto principal) pero puede expresar una inclinación adicional por otro $\mathrm{u}$ otros candidatos (voto auxiliar).

Este sistema de Hare o del cociente natural, llamado así en honor de Thomas Hare, quien en su libro La maquinaria de la representación, publicado en 1857, propuso su utilización conjuntamente con el sistema del voto único transferible, presenta el problema que, a consecuencia de que la votación efectiva de las distintas listas en muy raras ocasiones es un múltiplo exacto del cociente, casi siempre su aplicación deja votos sobrantes y residuos y puestos o curules sin distribuir, dando origen a desequilibrios en la igualdad de los elegidos frente al caudal de la población que representan.

- El método Geyerhahn, que requiere, a su vez, que el país se divida en circunscripciones uninominales para cubrir con el sistema mayoritario la mitad de las curules que se deben proveer. Para la asignación de la otra mitad se adopta el sistema de la representación proporcional, con el fin de que a cada lista le correspondan tantas curules cuantas veces quepa el cociente electoral en cada una de ellas.

Para efectos de la representación proporcional aludida, el país se considera como una sola circunscripción que coincide con la extensión total de su territorio. Este sistema ha sido utilizado en Alemania.

\section{Causas comunes de inelegibilidad}

Por regla general rige el principio de que el ciudadano que reúna las condiciones para ser elector puede también ser elegido. Sin embargo, fuera de las causas de incapacidad ya examinadas a propósito de los 
electores, existen otras especiales en relación con los candidatos a ser ungidos por el voto según la representación popular a la cual aspiren. Como es natural, tales causas varían según la legislación de los diferentes países; pero desde un punto de vida doctrinal, estas se pueden agrupar en las siguientes:

\section{Causas que determinan incapacidad}

Son las que provienen de la falta de aquellas condiciones psicofísicas y morales de la persona, necesarias para el desempeño de la función pública, pues lo mismo que para el electorado activo, en relación con el pasivo (los elegibles) se requiere la ciudadanía, un mínimo de edad, no haber perdido los derechos políticos a consecuencia de lo prescrito en la ley, ni padecer enfermedad que altere gravemente las facultades de entender o de querer. No tendría capacidad para ser elegido, quien careciera de algunos de los requisitos enunciados anteriormente.

\section{Causas de inelegibilidad para ciertos cargos}

Estas pueden provenir del hecho de ocupar el candidato ciertos cargos públicos o de estar comprometido en actividades contrapuestas a los intereses generales de la comunidad, entre ellas:

- Quien estuviere cumpliendo la pena de interdicción de derechos y de funciones públicas, bien sea en forma principal o accesoria.

- Quien haya sido condenado por delitos contra el patrimonio del Estado.

- Quien hubiere perdido su investidura como congresista (senador de la República o representante a la Cámara).

- Quién hubiese sido revocado en su mandato como alcalde o gobernador.

Por su parte, el artículo 299 de la Constitución y el Decreto 1222 de 1986 fijan las inhabilidades para ser elegido diputado a la Asamblea Departamental.

Los artículos 303 y 304 de la Carta, limitan las candidaturas a los aspirantes a la Gobernación y las Leyes 136 de 1994 y 617 de 2000, 
fijan las inhabilidades para ser elegido alcalde distrital o municipal y personero distrital o municipal (agente del Ministerio Público) de cualquier municipio del país, salvo Bogotá, pues a estos aspirantes, dice el Decreto 1421 de 1993, se les aplicará el régimen de inhabilidades e incompatibilidades que la Constitución fija para ser elegido presidente de la República.

Finalmente, el artículo 312 Superior, el artículo 43 de la Ley 136 de 1994, y el artículo 28 del Decreto-Ley 1421 de 1993, establecen respectivamente las inhabilidades para ser elegido concejal de cualquier municipio de Colombia y de Bogotá, D.C.

\section{El procedimiento electoral}

Para el ejercicio del sufragio es necesario que se cumpla un dilatado proceso electoral cuyas fases principales se enumeran a continuación.

\section{Inscripción o registro en las listas electorales}

Cuando un ciudadano quiere figurar como elector activo, lo primero que debe hacer es inscribirse en un listado electoral que para tal efecto confeccionan los funcionarios competentes. La adquisición del documento de ciudadanía es requisito previo para la inscripción electoral y esta, por lo general, se lleva a cabo en el lugar de residencia del interesado.

Las listas son permanentes, es decir que en cada distrito o municipio debe haber una lista electoral pronta a ser utilizada en cualquier momento, aun cuando no haya elección en perspectiva inmediata. Esta continuidad de los listados electorales se justifica no sólo ante la posibilidad de que el cuerpo electoral tenga que actuar en fecha imprevista (en caso de disolución de las Cámaras en países de sistema parlamentario), sino para asegurar la regularidad y corrección de las listas, impidiendo de esta manera la presentación de numerosos y serios problemas que ocurrirían si se dejase la confección o actualización de aquellas para los días inmediatamente anteriores a la elección. 


\section{Señalamiento de fecha para los comicios}

Este acto se cumple cuando el gobierno convoca a elecciones de acuerdo con lo dispuesto en la respectiva legislación.

\section{Agitación electoral}

Conocido el día en que tendrán lugar las elecciones se da principio a la agitación electoral a cargo de los partidos y de los aspirantes a candidatos por las diferentes agrupaciones políticas.

El derecho a la libre expresión del pensamiento encargado a los llamados "pregoneros", permite el empleo de toda forma de propaganda hablada o escrita, excepto las que contraríen claros preceptos legales o principios fundamentales de moral pública.

\section{Presentación de candidatos}

En las democracias clásicas los encargados de este menester son los directorios políticos de los diferentes partidos, luego de que los candidatos sean acordados por los reales jefes de turno (como ocurre la mayoría de las veces) o en convenciones hábilmente planeadas para que determinen lo que se desea alcanzar. En ningún caso se permitirá a los ciudadanos pertenecer simultáneamente a más de un partido o movimiento políticos con personería jurídica, y tampoco ser candidato por más de un partido o para más de un cargo al mismo tiempo.

\section{Nombramiento de jurados de votación}

Las autoridades electorales designan jurados de votación en el número que determine la ley. En Italia cada jurado está formado por cinco escrutadores que presiden la operación del depósito de votos y el escrutinio.

Esos jurados de votación son los ciudadanos encargados por mandato legal, para desarrollar el proceso de las votaciones, contabilizar los tarjetones o los votos depositados en la urna y entregar, debida- 
mente diligenciadas, los resultados electorales en las actas diseñadas para ello.

Se exige para ser jurado, no tener más de 60 años de edad y ser ciudadano en ejercicio, razón por la cual, considero que en los lugares en los cuales, la ciudadanía común se excuse para participar como jurado por razones de seguridad en zonas afectadas por la alteración del orden público, miembros de la Policía Nacional, que es un cuerpo cívico armado, pueden ejercer como jurados de votación.

Además, pueden ser jurados de votación en Colombia:

- Los alumnos de décimo y undécimo grados de bachillerato.

- Todos los funcionarios y empleados públicos.

Sin embargo, están impedidos para ejercer dicha función pública:

- Las primeras autoridades civiles del orden nacional, seccional o municipal.

- Los candidatos a cargos de elección popular, ni su cónyuge o compañero(a) permanente o sus parientes hasta el segundo grado de consanguinidad o de afinidad, o primero civil, dentro de la respectiva circunscripción electoral.

- Los funcionarios de la jurisdicción contencioso-administrativa.

- Los miembros de directorios políticos.

- Los miembros de la fuerza pública.

- Los operadores del Ministerio de Telecomunicaciones, empresas de telefonía, los auxiliares de los mismos y los funcionarios de correos.

- Los parientes dentro del cuarto grado de consanguinidad, segundo de afinidad y primero civil, del registrador nacional, ni de los registradores departamentales, municipales o auxiliares, ni de los delegados del registrador.

- Quienes tienen funciones propiamente electorales.

\section{Testigos electorales}

Los directorios de los partidos o movimientos políticos que hayan inscrito candidatos, tendrán derecho a presentar ante los registradores listas de personas honorables, para que actúen como testigos elec- 
torales, uno por cada mesa de votación, para garantizar la pureza y publicidad de las elecciones. Es una función pública transitoria y las autoridades están obligadas a prestarles colaboración.

\section{Votación}

La votación generalmente tiene lugar en día domingo, por lo común desde las 8 a.m. hasta las 4 de la tarde. El elector, antes de depositar el voto, debe identificarse ante los miembros del jurado con la respectiva cédula de ciudadanía, a fin de confrontar el número de esta con el que figura en el listado. Pasado el acto de identificación el elector deposita la papeleta con el nombre del candidato o de la lista de candidatos en una urna preparada al efecto.

La mesa de votación se instalará a las 7:30 a.m., para lo cual se firmará un acta, se verificará la existencia de los correspondientes elementos y formularios y se mostrará al público la urna vacía para sellarla.

Los ciudadanos que padezcan limitaciones y dolencias físicas que les impida valerse por sí mismos, los mayores de 80 años o quienes tengan problemas avanzados de visión, pueden ir acompañados hasta el cubículo de votación. No obstante la ayuda no autoriza a los acompañantes para seleccionar o marcar los candidatos en las tarjetas electorales, pues siempre debe prevalecer el principio de secrecía del voto.

\section{Escrutinio}

Transcurrida la votación, el jurado da comienzo al escrutinio, consiste en contar los votos emitidos, anotando los que corresponden a cada lista o nombre, según el caso, de todo lo cual se deja constancia en un acta con los datos respectivos para que las autoridades electorales competentes apliquen el método D'Hondt, el del cociente electoral o el mixto, según lo dispuesto en la legislación de cada país, con el fin de hacer la adjudicación de curules conforme a los resultados obtenidos.

En Colombia dicha operación la verifica la Registraduría Nacional del Estado Civil cuando se trata de elegir presidente de la República; los delegados departamentales de la misma entidad para elección de miembros del Congreso, con segunda instancia ante la Registraduría 
Nacional, y para elección de diputados departamentales, y los delegados municipales para elegir miembros del respectivo Concejo Municipal. Para poder comenzar con el escrutinio, es necesario contar con la participación de los claveros, que son los funcionarios encargados de la guarda de los documentos electorales dentro del arca triclave, la cual está definida como un arca u oficina o local de tres cerraduras o candados en donde se introducen o guardan documentos electorales, la cual irá marcada exteriormente con el nombre del municipio correspondiente. $^{23}$

De las demandas que tengan que formular los interesados por hechos lesivos de la autenticidad del sufragio, conoce privativamente la jurisdicción de lo contencioso-administrativo.

El escrutinio está definido como el conjunto de actos electorales que regulan jurídicamente el resultado de las elecciones y debe estar regido por los principios de inmediatez, transparencia y publicidad.

Después de los escrutinios auxiliares o zonales, distritales y municipales, departamentales y nacional, según el caso. En ellos pueden presentarse reclamaciones sobre dicho procedimiento.

Las reclamaciones, que son doce, pueden presentarse ante los jurados de votación o ante las comisiones escrutadoras según el caso. Constituyen el mecanismo a través del cual se pueden impugnar ante las autoridades electorales competentes, los resultados arrojados en los escrutinios con las circunstancias de tiempo, modo y lugar que rodearon los mismos y en general el proceso de las votaciones. Son taxativas y excluyentes, lo cual exige que los hechos alegados coincidan con alguna de éstas, imponiendo que se invoquen causales por deducción o por simple analogía. Cabe indicar que el Consejo Nacional Electoral, mediante Resolución 5315 de 2003, determinó que las causales segunda, novena, décima y decimosegunda, no son aplicables a las votaciones de referendo.

\section{Bibliografía}

Acto Legislativo 01 de 1977, Congreso de la República, Colombia. Acto Legislativo 01 de 2003, Congreso de la República, Colombia.

${ }^{23}$ Fajardo Méndez, Jaime, Manual de derecho electoral, Bogotá, Ediciones Librería del Profesional, 2003, p. 20. 
Acto Legislativo 01 de 2003, Congreso de la República, Colombia. Acto Legislativo 01 de 2009, Congreso de la República, Colombia. Decreto 2559 de 1997, Congreso de la República, Colombia.

Fajardo Méndez, Jaime, Manual de derecho electoral, Bogotá, Ediciones Librería del Profesional, 2003.

Figueroa Jiménez, Álvaro Enrique, Derecho, elecciones y democracia en Colombia, Bogotá, Editorial Tribuna-Textos Jurídicos, 1997.

Ley 403 de 1997, Congreso de la República, Colombia.

Ley 815 de 2003, Congreso de la República, Colombia.

Ley 131 de 1994, Congreso de la República, Colombia.

Ley 134 de 1994, Congreso de la República, Colombia.

Ley 43 de 1993, Congreso de la República, Colombia.

Olano García, Hernán Alejandro, Constitución Política de Colombia-Concordada, 2a. ed., Bogotá, Ediciones Doctrina y Ley, 2011.

Olano Valderrama, Carlos Alberto y Olano García, Hernán Alejandro, Derecho constitucional general e instituciones políticas. Estado social de derecho, 3a. ed., Bogotá, Ediciones Librería del Profesional, 2000. 